\title{
A Critical Study on the Contributions of Training Program Application in the Success of Organization Development and Training Processes in Oman A Case Study of TRC
}

\author{
Khalid Rashid Hamed Alabri \\ Middle East College \\ Dr. Maria Teresa G. Matriano \\ Middle East College
}

\begin{abstract}
Most government sector in the region face the issue of lack of local training provided for the employees. Research shows the constant development in the workplace and the need to develop employee knowledge and experience through constant training. To provide an easy solution for sectors and institutions to communicate and present their needs when it comes to training programs and courses, this research aims to create a platform through mobile application to bring together government sectors and local teaching institutions to provide required training programs for employees. This is done by investigating on the issues of accessibility of the Training programs in Oman, evaluate the importance and impact of training programs on employee development, introduce a training program application and investigate on the usage benefits on the Training Program Application within government sectors. Since this research introduces a new concept, it asks: What are the issues facing organizations when it comes to training programs? To what extent does the application influence employee development? How complex is the development of a Training Program Application? And, how will government sectors benefit from the Application?
\end{abstract}

Aside from the literature review, interviews were also made with local experts from government sectors to shed light on the effect of lack of training on the current employee situation. Online surveys were distributed to a group of employees from different departments in some local government sectors. Analysis of the responses shows the need and interest of employees on the issue of training, as the majority of employees have an interest in local courses and would use the application to benefit their work experience. The results indicate the Training Program Application affects positively on the government sectors and can provide all the needed training courses with less cost and influence employees.

\section{Introduction}

Workplace training is a program that enables representatives to learn explicit information or abilities to improve execution in their present jobs. Improvement is increasingly sweeping and spotlights on worker development and future execution, as opposed to a prompt occupation job. Great training and advancement programs help you hold the perfect individuals and develop benefits. As the fight for top ability turns out to be progressively focused, worker preparing and improvement programs could really compare to ever. Employing top ability requires significant investment and cash, and how you connect with and build up that ability from the time they are first on boarded impacts maintenance and business development (AllenComm, 2019).

Sectors that puts resources into its workers makes progress in the commercial center. This interest in human capital must start with the contracting procedure and proceed all through the worker's residency with the organization. A persistent interest in human capital methods giving a far- 
reaching and evenhanded business bundle that, at the base, comprises of a sensible pay scale, advantages, and training.

As innovation improves and the extension of competition expands, government and private divisions need to put resources into boosting their workforce experience. Generally, sectors need to discover courses to train the employees locally, yet that would be a challenge, as there is not any immediate connections between these divisions, and the establishments that give courses. Typically, these parts pass up on some respectful chances because of the absence of correspondence between the government and private sectors and the institutions, as no immediate stage gives information of these courses to the general population.

\section{Statement of the Problem}

This dissertation will study the issue of Training Programs within organizations in Oman. Most organizations, government or private face challenges when it comes to training employees. Whereas, every employee or group of employees need a different program to gain knowledge in their specific field of work.

As innovation improves and the extension of rivalry builds, organizations need to put resources into boosting their employees experience and knowledge. Generally, organization need to discover courses and programs to train the workers broadly, yet that would challenge, as there is not any immediate connections between these organizations, and the institutions that give courses.

Typically, these parts passed up on some aware chances due to the absence of correspondence between the organizations and the institutions, as no immediate stage gives information of these courses to people in general.

Another obstacle facing organizations is the absence of trained experts teaching such required courses. However, most institutions can provide remote experts yet require an enormous number of applicants to cover the expense of bringing the mentor or expert. For the most part, every division will require preparing a couple of employees in a particular course; this would be troublesome and exorbitant for the organization just as the area to give a teacher to train a couple of workers.

Another encounter confronting the sectors is the absence of trained experts showing such required courses. However, most organization can give remote experts yet require an expansive number of members to take care of the expense of bringing the mentor or expert. These discussions will be recognized over the course of the research, and proper arrangements will be contemplated to achieve required outcomes. Since this is, the period of web-based life, advanced cells, an answer for this issue can be by building up an application that unites all sectors, and learning institutions. Whereas, institutions can show every single accessible course or preparing projects and sectors can know about every accessible course. In addition, specific departments can demand explicit courses or preparing programs, where organizations can contend to furnish courses with their necessities, determinations and costs.

\section{Outcomes of the Study}

\section{Training Programs Accessibility.}

The study will identify the lack of training courses provided by institutions for organizations, and to what extent does this affect the workforce development. There are a few training institutions around the region but the issue facing most organizations is the accessibility and finding the accurate training program for specific fields of work. Most government sectors in Oman have various departments, though these departments are similar in most sectors; finding the fitted course or training program for each department is challenging. As most training institutions have 
limited courses and training programs, which is difficult for specified departments.

The critical evaluation results on the importance and impact of Training Programs on Employees Development.

Organized training and advancement program guarantees that employees have a predictable encounter and foundation learning. The consistency is especially significant for the organization's essential approaches and methodology.

All workers should know about the desires and strategies inside the organization. This incorporates wellbeing, separation and regulatory undertakings. Putting all workers through normal preparation in these territories guarantees that all staff individuals at any rate have presentation to the data.

Investigate the development of the Training Program Application.

To develop a mobile Application, hiring an expert can be considered the best approach. To start with, it is required to gather information about the available institutions willing to register in the application, then gathering data on all required training courses and programs. After gathering all the data required to develop the Application, the expert then can work on developing the App and presenting it to the Ministry of Manpower for approvals. After approving the application, it can then be marketed to all government organizations and presented to organizations for registering.

The critical evaluation results on the status of The Research Council's training programs.

As a case study, this dissertation will look into a government sector (The Research Council) and consider collecting data by interviews and handing out questioners to various employees within the organization to gather information on the current training program status. Whereas, TRC is considered one of the newest government sectors and has new developing departments. Employees need to develop their knowledge on the work field and explore the advancement of their work. As TRC is expanding its horizon with different and new scopes of work.

\section{Section 2}

\section{Scope of the Study.}

This study attempts to evaluate the issue of lack of training programs and courses provided locally to government and private sectors, how is this matter affecting the current development of our workforce. Moreover, the research will deeply explore the development and presentation of the application on the selected case study. Determining the benefits and challenges of installing an application that would serve the needs of various sectors to improve the skills of the employees. The research will conduct primary data collection by initiating interviews within the different hierarchy of the sectors, as well as conducting questionnaires and gathering descriptive qualitative data.

\section{Limitation of the Study.}

Seeing that Oman is a developing country, providing and developing such, application could be costly for the institutions. Smartphone apps tend to be costly and institutions would need to employ a specialist to provide the courses, maintain, access and report all data sent and received through the application.

Resources and quantitative research is limited to a single government sector as it is challenging to gather data from different sectors. As this dissertation would be cohesive of a single persons work, allocating data from different sources would require authorization to gather information that would 


\section{Journal of Student Research}

Fourth Middle East College Student Research Conference, Muscat, Sultanate of Oman

be difficult to acquire. To generate a full understanding of the government sector training requirements, the research will need to deeply investigate the lack of resources in the government sectors. Whereas, this would be considered as critical and private information that is no accessible by the public. Some information can be provided by presenting formal requests to the government sectors. However, the process is long and requires a few approvals from different department head. The lack of time in this research restricts the matter of getting the required information.

The study will not cover the stages of developing the physical application as there are not enough resources to cover application development as well as limitation of time. Further studies should consider developing the application and testing it on a number of government institutions to generate a more accurate result on the benefit of contributing this application.

\section{Significance of the Study.}

The study composed, collected, and examined data among professional government sectors including employees from different fields and departments. The results of the study will benefit various groups of the government sectors as follows:

Training and advancement is an issue paid great attention to by the Government of Oman; its Vision 2020 accentuates the requirement for improvement of the workforce and the successful administration of its abilities. Most organizations have comparable offices inside, and overall require comparative instructional classes. In the event that these courses are provided locally, the sector would not have to spend much to send workers for training internationally; in addition, this would influence the national economy emphatically. While, more employees would gain expertise and therefor benefit the nation. Likewise, the In Country Value would increment, as local training institutions with benefit from providing their services and government and private sectors will benefit from training employees nationally.

After the financial crises sectors drew back massive spending, where the effect spread to the workforce. By developing the application that would gather all available courses and training programs locally as well as gathering all the local sectors with employees needing training, the sectors would have reduced the cost of spending on courses and gain the development and growth of its workforce. On the other hand, local institutions would find it easier to present different courses and sustain the needs of the sectors.

Government sectors will benefit from this application by creating a platform where organization and institutions come together to find training and teaching opportunities for employees from different fields of work. Institutions register in the App and present all training opportunities, and organization register to find suitable programs for their employees. The application can be adopted by the Ministry of Manpower and would cost organization a small fee to register. As developing such an App is costly the Ministry can require a fee from the institutions that provide the training courses for each registered candidate. This way the cost of the Application development and maintenance can be covered.

\section{Experimental Procedures}

Research Methodology is an approach to efficiently mind out the examination issue. It might be comprehended as a study of considering how research is done logically. It considers the different advances that are commonly received by an analyst in examining the exploration issue alongside the rationale behind them. It is vital for the specialist to know the exploration strategies/systems yet additionally the approach. Analysts do not just need to realize how to build up certain lists or tests, how to ascertain the mean, the mode, the middle or the standard deviation or chi-square, how to apply specific research strategies. Yet they likewise need to know which of these strategies or systems, are important and which are not, and what might they mean and demonstrate and why. 


\section{Journal of Student Research}

Fourth Middle East College Student Research Conference, Muscat, Sultanate of Oman

Methods in this study will consider a wide range of library study as the idea of the research is somewhat new and yet to be established.

\section{Research Design}

Research approach are plans and the techniques for research that range the means from wide suppositions to nitty gritty strategies for information gathering, examination, and understanding. This arrangement includes a few choices, and they need not be taken in the request in which they sound good and the request of their introduction here. The general choice includes which approach ought to be utilized to examine a theme. Advising this choice ought to be the philosophical presumptions the scientist brings to the investigation; methodology of request (called research design); and explicit research strategies for information gathering, examination, and understanding. The determination of an exploration approach is likewise founded on the idea of the examination issue or issue being tended to, the analysts' close to home encounters, and the spectators for the investigation. For the purpose of the study, the research design used will be descriptive and exploratory. This is done through research surveys and interviews. The study requires descriptive analysis on the matters relating to lack of training and benefits of TPA within organizations. Since the study is somewhat new and it presents a new idea for government organizations exploratory research will be conducted on previous studies and concepts on training needs and adopted methods.

\section{Research Methods}

Research methods might be comprehended as each one of those strategies/methods that are utilized for conduction of research. Research strategies or techniques, along these lines; allude to the techniques the researchers use in performing research activities. At the end of the day, each one of those techniques, which are utilized by the researcher over the span of contemplating his examination issue, are named as research strategies. Since the object of research, especially the connected research, is to land to an answer for a given issue, the accessible information and the obscure parts of the issue must be identified with one another to make an answer conceivable.

\section{Figure Legend}

To start the analysis, the research looked into the average age group of the employees, most of which were interested in the matter of training.

Age 


\begin{tabular}{|c|c|c|c|c|c|}
\hline & & Frequency & Percent & $\begin{array}{l}\text { Valid } \\
\text { Percent }\end{array}$ & $\begin{array}{l}\text { Cumulative } \\
\text { Percent }\end{array}$ \\
\hline \multirow[t]{6}{*}{$\overline{\text { Valid }}$} & $18-25$ & 4 & 2.0 & 2.0 & 2.0 \\
\hline & $26-30$ & 56 & 28.0 & 28.0 & 30.0 \\
\hline & $31-35$ & 71 & 35.5 & 35.5 & 65.5 \\
\hline & $36-40$ & 64 & 32.0 & 32.0 & 97.5 \\
\hline & $40+$ & 5 & 2.5 & 2.5 & 100.0 \\
\hline & Total & 200 & 100.0 & 100.0 & \\
\hline
\end{tabular}

Figure 1. Frequency test for age groups

Since the survey was sent through emails and not approaching the employees personally, a brief introduction was stated on the email about the research topic. The chart shows the age group mostly interested in the concept of training. Between the age 30 and 40 years employees seem to be mostly interested when it comes to training.

More mature individuals will in general be more situated toward keeping up business as usual than more youthful ones, and they are required to be more reluctant to participate in new ability training. One potential purpose behind the lower cooperation of more seasoned workers in learning and formative exercises is that they may encounter specific requirements because of the organic changes related with maturing. Maturing is frequently connected to a decrease in psychological and scholarly capacities (Ackerman, Beier, and Bowen, 2009). In our present society where performing various tasks is the standard instead of the special case, individuals of midlife or more may feel less equipped than more youthful grown-ups. Older specialists may accept that older individuals by and large are less ready to learn as well as they accept that they themselves are never again fit for adapting new abilities. One way or the other, they will in general have less confidence in their capacities to adapt new aptitudes (Touron and Hertzog, 2004), which may lessen their preparation and improvement readiness. In spite of the fact that this suggestion is conceivable for the gathering of more seasoned specialists as for a short time, there are obviously exemptions to this general principle. Some more seasoned laborers may stay keen on learning and improvement while others may not. These distinctions among more seasoned specialists could identify with their eccentric convictions, the help they see from their workplace, and the convictions and practices of significant others (e.g., Nauta, Van Vianen, Van Der Heijden, Van Dam, and Willemsen,2009)

According to table (4.2) most participants indicated they have attended more than one course in their time of their employment. 


\section{courses}

\begin{tabular}{|c|c|c|c|c|c|}
\hline & & Frequency & Percent & Valid Percent & $\begin{array}{c}\text { Cumulative } \\
\text { Percent }\end{array}$ \\
\hline \multirow[t]{6}{*}{ Valid } & none & 7 & 3.5 & 3.5 & 3.5 \\
\hline & $1-5$ & 6 & 3.0 & 3.0 & 6.5 \\
\hline & $1-5$ & 176 & 88.0 & 88.0 & 94.5 \\
\hline & $6-10$ & 10 & 5.0 & 5.0 & 99.5 \\
\hline & more than 10 & 1 & .5 & .5 & 100.0 \\
\hline & Total & 200 & 100.0 & 100.0 & \\
\hline
\end{tabular}

Figure 2. Number of courses attended

Figure 3. Number of courses attended

As per the chart in figure (1), most of the employees who have participated in the survey indicate that the number of courses they attended throughout their professional life does not exceed five courses. As figure (1) shows majority of the participants are aged between 30 and 40 years old. Supposedly, a person would get a job at the age of 24, therefore, roughly estimating an employee would attend five training courses in a ten-year timeframe, one local course every two years is considered a very low rate for employees in a developing country, indicating the lack of training programs provided for employees.

Figure 4. Correlation test between the age groups and the number of courses attended

Correlation is a factual strategy that shows how emphatically two factors or variables are identified with one another or the level of relationship between the two. The connection coefficient ought to consistently be in the scope of - 1 to 1 . There are three kinds of connection:

1. Positive and negative relationship: When one variable moves a similar way, at that point it is called positive connection. When one variable moves a positive way, and a subsequent variable moves a negative way, at that point it is said to be negative relationship.

2. Direct and non-linear or curvi-direct relationship: When the two factors change at a similar proportion, they are known to be in direct connection. At the point when the two factors don't change in a similar proportion, at that point they are said to be in curvi-straight connection. For instance, on the off chance that deal and consumption move in a similar proportion, at that point they are in direct connection and in the event that they don't move in a similar proportion, at that point they are in curvi-straight relationship.

3. Basic, incomplete and numerous relationships: When two factors in connection are taken in to think about, at that point it is called basic relationship. When one variable is a factor variable and as for that factor variable, the connection of the variable is considered, at that point it is a halfway relationship. At the point when various factors are considered for relationship, at that point they are called numerous connections. 
Figure 5. Correlation graph between the age and number of courses

Based on figure (10) the test shows a significant relationship between the employee's age and the number of courses attended. Whereas, $\mathrm{r}(198)=0.434, \mathrm{p}=.000$ which shows a positive linear relationship, the older the employee is the more courses they attended.

Figure 6. Crosstabultation between the age and prefer ability to choose courses

The crosstabulation table (4.4) shows the breakdown of number of participants in each age group and their prefered option in choosing the course. They were given three options where they can choose the training course: 1) the employee chooses, 2) the entity they work for chooses,3) or, on who chooses the course.

Figure 7. Chi Square Test for table (4.4)

The Chi-square test in table (4.5) shows the relationship between two categorical variables, this statistical analysis shows a single number that tells the amount of difference existing between the observed count and the amount expected if there is no relationship in the population.

Table (4.6): cross tabulation table between employee age and their interest in choosing courses

Table (4.5) and (4.6) show the relationship between the age of the employee and their desire to choose the training courses themselves or if they would want the employer to choose from them is determined by Chi-square test. The null hypothesis is stated at $\mathrm{HO}=$ No relationship and $\mathrm{H} 1=$ Relationship. It is stated that the degree of freedom (df) $=8$ and the Chi square test statistic is 12.008. from that the $\mathrm{p}$ value for this statistic is 0.151 . the $\mathrm{p}$ value is considered to be on the low side but is not rejected as it is higher than $5 \%$. this states that a slight relationship between the age of the employee and the desire to choose the course whereas, $\mathrm{x} 2(8, \mathrm{~N}=200)=12.008, \mathrm{p}=0.151$.

This study showed that the age group mostly interested in training and development was between 30 to 40 years old. Research on the connection between work capacity and age has been reliably directed. The aftereffects demonstrate that when individuals arrive at a specific age, their work capacity altogether diminishes. As per further look into, as laborers keep on maturing, their work capacity keeps on diminishing.

Nevertheless, there are likewise differentiating examination results. For instance, the distinctions in physical capacity among old employees (the age of 50 and above) are generally littler than those among youthful laborers (the age of 40 and under); specifically, the previous can keep up certain physical capacities to perform fundamental errands. In like manner, the point of the present examination was to explore the work capacity of laborers matured 55 or more seasoned working in substantial industry and to inspect the connections between their ages, the quantities of years they worked, and their intellectual capacities (Gall B, Parkhouse,2004).

\section{Experimental Procedures}

\section{Interviews}

The interviews showed the critical analysis of training needs within government sectors. Mrs. Alrawahi stated: "I have been working in this institution for about one year now, since I stated I did 
attend one local course, but it was not directly related to my field of work", she included: "Since I am working in the legal department I much rather apply to courses that benefit my legal skills. Training is very important especially that my job requires me to be constantly updated with new regulations and ministry decisions." Mrs. Alrawahi explicitly encouraged the idea to TPA; she said that employees know exactly their own weaknesses, which elaborates the need to improve.

Mr. Alalawi defined training as the motor that keeps the employee running. "Employees need to be kept motivated constantly, the need of improving should be reinstated on a continous manner." He said. "I believe in innovation, training should be a workplace requirement for employees from the lowest level to general managers". He added, "Why does the TPA only focus on training? It can include all aspects of knowledge gain and motivation. All types of workshops, seminars, conferences and classes should be incorporated under one platform".

The interviews supported the basis of the study, showing acceptance from candidates on the idea of presenting and providing training courses through the smart phone platform. Engaging with participants and discussing the issue of the study contributed deeply to the core of the issue. Employees have the right to invest in themselves and believe their entity and organization should consider developing them.

\section{Sample collection}

The study aims to understand the nature of the employees impact with the contribution of the TPA, the surveys send out to the employees is an effective technique to generate a realistic understanding of the training statue within government sectors.

The survey was emailed and sent through WhatsApp to about 500 employees in various government sectors, with a brief description on the topic and the study, to generate an understanding before answering the questions. From the 500 distributed surveys 200 completed surveys came back.

Figure 8. Sample size Calculator

The figure above shows the recommended sample size for the study, according to the National Centre for Statistics and Information website, the number of local employees in the government sectors in Oman in 2018 was about 195,236. The survey was to 500 emails gathered from different sources and got research got only 200 responses back.

\section{Sample Technique and Sample Size}

For the study a random sample technique will be used to collect data, the aim is to get as many respondents to the survey as possible, for this technique the research will use Cochran's sample test (ThemeHorse, 2019) as followed:

The value of $p=0.5$ and the study can suppose a 95\% confidence level, and $5 \%$ error margin. At $95 \%$ confidence the value of $\mathrm{Z}$ is 1.96 as normal tables:

$((1.96) 2(0.5)(0.5)) /(0.5) 2=385$

The null hypotheses $n 0$ is Cochran's sample size recommended, the population size is $\mathrm{N}$, and $\mathrm{n}$ is the adjusted sample size. The calculation for our sample size would be:

$385 /(1+(384 / 200))=131.8$

The sample size recommended for the study would be 132 .. 


\section{Results}

\section{Objective One: Accessibility of The Training Programs by different organizations in Oman}

The study indicated a clear difficulty facing most employees and organizations in the matter of accessibility when it comes to local training courses. Some employees find it challenging to find training programs that suit their specified need, whereas, others (specifically in the fields of IT and engineering) state that many local institutions provide training courses for their development.

As per the surveys distributed to a wide range of employees from various departments in government sectors, the majority of responses indicated the lack of current training programs provided locally. Some responses showed more than 5 years of working in the same position without a single training course presented to the employee. Training and improvement got connected at the hip. All plans ought to survey the employees' execution, staff inclination yet more significantly ought to pass on to the staff that a long haul profession and advancement plan is set up for them and what the objectives are. It is critical to consider frame of mind just as execution when giving assignments and advancing staff.

There are a few foundations which have frameworks wherein advancement depends on a blend of capabilities and long periods of administration, not considering the genuine range of abilities of the worker under thought, nor their capacity, or scarcity in that department, to perform at a more elevated amount of obligation. This is de-persuading since activity is decimated, responsibility is tempered and execution will in general become adversely affected.

Advancement must be considered because of a vocation very much done as per long haul profession and improvement plans - where the employee is relied upon to be, at what level, over what timeframe, mulling over a profession that is anticipated to proceed until retirement age is come to. Staff inclination, when attainable, ought to be mulled over when plans are drawn out as this makes more prominent purchase in to the choices made. It is significant that these plans ought to be imparted to them. Along these lines, staff realize that their boss contemplates them as apparatuses worth creating and now and again as future managers, directors, and so on. (al Kharusi, 2019).

\section{Objective Two: Importance and Impact of Training Programs on Employees}

In numerous sectors in Oman, employees who are performing great and accomplishing their objectives are not perceived but rather their managers/directors are given credit, which prompts lower resolve among employees. This issue is exacerbated in numerous private organizations in the sultanate, as mostly, the employee will in general be Omani nationals, and the superior, in many examples, expatriates. Particularly, when national staff who are the foundation of a division and who know their obligations back to front are made to train purported 'specialists' who ought to innately not require this training as they have been gotten to bestow their mastery, and not pick up it at work, while acquiring considerably more than the staff training them.

This further demotivates staff, making undesirable obstructions, and no uncertainty further lessens driving force and responsibility. Being disregarded is the most exceedingly awful hit to any ability particularly in your own nation.

The study showed major interest in the employees when discussing the issue of training. Training empowers development for workers over any number of businesses. Employees who are trained will in general perform greater to the individuals who get no training and furthermore will in general feel increasingly satisfied. In that capacity, training and initiative advancement ought to be made 
accessible to all workers.

The study showed the interest of employees in training overall. Providing the type of training programs differed with different opinions. Employees in IT and Engineering departments stated that they have accessibility to local training programs and courses and within their departments. As most training institutions in Oman provide many training courses specializing in these fields. But when querying about fields that are somewhat new, or developing it has been shown that local training programs are rarely found. Institutions do not have the capability to bring in experts to train few employees at a time, and government institutions are not aware of the training program availability. As it is difficult to get all government sectors to communicate on required programs for their employees.

\section{Objective Three: The Development of the Training Program Application}

Technology has improved the manner in which the world conveys, and with that insurgency, the manner in which we train our workforce. By using innovation in energizing and creative ways, ordinary training can be modified and conveyed to clients quicker than any time in recent memory. Training is always showing signs of change and improving gratitude to the utilization of inventive arrangements. By adjusting our training to mirror the patterns, our courses become increasingly useful to employees. Training can be structured in light of the employee, and as available as workable for our representatives (Kelso, 2019).

Most survey responses recommended accessibility to training courses through mobile application. Whereas, everyone now is using a smart phone, and this devise is used as a personal calendar, social communication, reminders, appointments and so on. Employees want to have access to training programs and have the flexibility to choose the course they require based on their own professional need.

When it comes to developing a mobile application many factors should be taken into consideration. Starting with a simple idea and ending with the development on the physical application.

\section{Objective four: Usage benefits of the Training Program Application within organizations.}

The study indicated employees seek to develop themselves through various means, where they mostly encourage their employer to enroll them in any program that is considered beneficial for the professional careers. Putting the idea out of a TPA that could be adopted by their organizations grabbed employees attention. Throughout the interview, process employees questioned the physical availability of the TPA and its content.

Many studies showed offering proficient advancement training courses enables workers to perform better and sets them up for places of more prominent duty. Nevertheless, it can likewise enable businesses to draw in top employment applicants, hold their best laborers and recognize future pioneers. In addition, continuous expert improvement is speaking to numerous workers today who are hoping to keep their aptitudes applicable in a quickly evolving world.

National, territorial, and other government substances have a personal stake in building up a solid and steady work power in their general vicinity. An appropriately arranged work pool pulls in and holds businesses, decreases joblessness, and takes into account satisfaction of cultural needs. It empowers a territory to be focused with different areas (e.g., different states, locales, or nations). Be that as it may, government assets are constrained, so keen choices must be made about where and how assets are allotted (and which strategies ought to be bolstered) to help in workforce improvement. Information about what aides and impedes preparing adequacy is basic. 


\section{Journal of Student Research}

Fourth Middle East College Student Research Conference, Muscat, Sultanate of Oman

Though the Application subject to the study cannot be physically tested, the study indicated a range of benefit caused if this application is to be adopted. The research stage is finalized by this study and a recommendation can be sent out to the specified government organization for presentation and testing the outcome on some government sectors.

\section{Conclusion}

Training is a fundamental aspect in and employees' professional life, early in the research it has be stated that the need to keep up with the market development requires effort from government sectors and training institutions. Employees are the drive of the organizations and successful organizations results in a developed country.

This application will result in closing the gap between governments and training institutions by creating a platform where organization and institutions come together to find training and teaching opportunities for employees from different fields of work. Institutions register in the App and present all training opportunities, and organization register to find suitable programs for their employees. The application can be adopted by the Ministry of Man Power and would cost organization a small fee to register. As developing such an App is costly the Ministry can require a fee from the institutions that provide the training courses for each registered candidate. This way the cost of the Application development and maintenance can be covered.

Throughout the employees' professional life, they are always looking for ways to improve and develop, most employees seek training opportunities outside the work place to gain knowledge and climb up the organization hierarchy. Based on the study and the collected information employees seek development in any way, to be précised the easier the accessibility the better and interested the employee is.

Taking into consideration the subject of research, specific methods or research has been chosen to obey the need of the study. Moreover, it provided the tools and techniques used to generate the data collection needed to deliver a full understanding of the requirements needed to fulfill the study. Throughout the process of the data gathering, it was becoming clear as to what extent the application is beneficial to local sectors and the degree to improvement it will cause the employees within new-ish fields of work.

The idea of this study is to contribute a new concept in the training procedure, widening the training opportunities for all employees generates and equal feel with the workplace. Every employee has the right to access and get training and not only the employees working the general fields. When all training require are provided locally, the benefits will rise. Less spending will be on international training courses, local experts will be generated and productivity increases. The Training Program Application is a window to achieve their goals, with the correct support and maintenance from the desired sectors.

\section{Acknowledgements}

Throughout my work on this dissertation, I have received a great role of support and aid. To start with, I would like to thank my Supervisor Dr. Maria Teresa G. Matriano for her constant support and expertise in the fundamentals of writing techniques; formulating the research topic, methodology, literature review and the hard work, she put to provide all the needed materials to finalize the research.

This work would not have been possible to accomplish without the support of my colleagues and mentors, I am grateful to all those whom I have had the pleasure to work with during the course of this dissertation among other projects and assignments. 


\section{Journal of Student Research}

Fourth Middle East College Student Research Conference, Muscat, Sultanate of Oman

To all agencies who provided much needed information and professional directions and guidance to accomplish all the stages of this dissertation writing on a professional level.

I would like to thank for the most important mean of support throughout my MBA studies, my family and friends. I appreciate their full support and encouragement to accomplish my studies.

\section{References}

AllenComm. (2019). what is Employee Training \& Development? | AllenComm. [online] Available at: https://www.allencomm.com/what-is-employee-training-development/ [Accessed 1 May 2019].

Ashwini, A. (2017). What Are The Various Phases Of Mobile App Development?. [online] Medium. Available at: https://medium.com/swlh/what-are-the-various-phases-of-mobile-appdevelopment-4f0a1748e619 [Accessed 21 Aug. 2019].

Al Kharusi, R. (2019). Omanisation - training and development - Muscat Daily. [online] Muscatdaily.com. Available at: https://muscatdaily.com/Archive/Stories-Files/Omanisation-trainingand-development-1 kyj [Accessed 21 Aug. 2019].

Auer, M. (2019). Mobile Technologies and Applications for the Internet of Things [S.l.]: Sringer.

Berg, B. L. (2007). Qualitative research methods for the social sciences. London: Pearson.

UKEssays. November 2018. Reliability and Validity in Research. [online]. Available from: https://ww w.ukessays.com/essays/psychology/the-reliability-and-validity-psychology-essay.php?vref=1 [Accessed 1 August 2019].

Creswell, J. W. (2013). What is mixed methods research [video file]. Retrieved from https://www.youtube.com/watch?v=10aNiTlpyX8

Corporate Finance Institute. (2019). Employee Training and Development - Overview, Benefits and Methods. [online] Available at: https://corporatefinanceinstitute.com/resources/careers/softskills/employee-training-and-development/ [Accessed 2 May 2019].

Dictionary.cambridge.org. (2019). Meaning in the Cambridge English Dictionary. [online] Available at: https://dictionary.cambridge.org/dictionary/english/course [Accessed 5 Aug. 2019].

Douthat, J. (1970). Accounting for personnel training and development costs. Training and Development Joumal, 24(6), 2

Elnaga, A. and Imran, A. (2013). The effect of training on employee performance. European Journal of Business and Management, 5(4), 137-147.

Fidelity.com. (2019). What Are Sectors And Industries? A Guide to Frequently Asked Questions Fidelity. [online] Available at: https://www.fidelity.com/learning-center/trading-investing/marketssectors/what-are-sectors-and-industries [Accessed 27 Aug. 2019].

Frost, E. (2014). Economic Development of Oman. [online] International Banker. Available at: https://internationalbanker.com/finance/economic-development-oman/ [Accessed 2 May 2019].

Gall B, Parkhouse W: Changes in physical capacity as a function of age in heavy manual work. Ergonomics, 2004, 47: 671-687

Garfinkle, J. (2019). Power of an Engaged Workforce | Article. [online]

Garfinkleexecutivecoaching.com. Available at: https://garfinkleexecutivecoaching.com/articles/busi 


\section{Journal of Student Research}

Fourth Middle East College Student Research Conference, Muscat, Sultanate of Oman

ness-intelligence-and-company-strategy/power-of-an-engaged-workforce [Accessed 27 Aug. 2019].

Gerber, R. and Lankshear, C. (2002). Training for a Smart Workforce. Hoboken: Taylor and Francis.

Geus, M. (2019). 5 Reasons to Implement Mobile Training This Year - Training Industry. [online] Training Industry. Available at: https://trainingindustry.com/articles/learningtechnologies/5-reasons-to-implement-mobile-training-this-year/ [Accessed 25 Aug. 2019].

Hasan, D. (2019). Oman employment: 'Graduates need training for future challenges'. Times of Oman. [online] Available at: https://timesofoman.com/article/99319 [Accessed 2 Jul. 2019].

Kee, J., \& Black, R. (1985). Is excellence in the public sector possible? Public Productivity Review, 9(1),25-34.

Kelso, S. (2019). Enhancing Training With Technology: How To Make The Most Out Of It eLearning Industry. [online] eLearning Industry. Available at:

https://elearningindustry.com/enhancing-training-right-use-technology [Accessed 21 Aug. 2019].

Khan, R. G, Khan. F. A. and Khan. M. A. (2011).Impact of training and development on organizational performance. Global Journal of Management and Business Research, 11(7), 63-68.

Kowalczyk, D. (2016). Research methodologies: Quantitative, qualitative, and mixed methods [video file]. Retrieved from http://study.com/academy/lesson/research-methodologies-quantitativequalitative-mixed-method.html

M. Hodgson, G. (2019). What Are Institutions?. [online] Geoffrey-hodgson.info. Available at: http://www.geoffrey-hodgson.info/user/bin/whatareinstitutions.pdf [Accessed 27 Aug. 2019].

Maor, M., \& Stevens, H. (1997). Measuring the impact of new public management and European integration on recruitment and training in the UK civil service, Public Administration, 75(3), 531-551.

Mabey, C. \& Graeme, S. (1997). Strategic Human Resource Management: For Change, Development \& Performance. New Delhi: Beacon Books.

Mohammed, A. A.W. \& Ingo, F. (2012). Of private sector fear and prejudice: the case of young citizens in an oil-rich Arabian Gulf economy. Personnel Review, 41(5), 609-629.

Merriam-webster.com. (2019). Definitions. [online] Available at: https://www.merriamwebster.com/dictionary/sector [Accessed 5 Aug. 2019].

Pandey, A. (2018). 10 Awesome Ways To Use Mobile Learning For Employee Training - eLearning Industry. [online] eLearning Industry. Available at: https://elearningindustry.com/mobile-learningfor-employee-training-10-awesome-ways-use [Accessed 2 Jul. 2019].

Peterson, J. (2004). Oman: Three and a Half Decades of Change and Development | Middle East Policy Council. [online] Mepc.org. Available at: https://www.mepc.org/journal/oman-three-and-halfdecades-change-and-development [Accessed 2 May 2019].

Studenthelp.secure.griffith.edu.au. (2019). What is a course?. [online] Available at: https://studenthelp.secure.griffith.edu.au/app/answers/detail/a_id/308/ /what-is-a-course\%3F [Accessed 27 Aug. 2019].

Swanson. R. A.. Lewis. D. R.. and Boyer. C. M. (1982). Industrial training and economic evaluation. In Program development and evaluation in the private sector. Oslo. Norway: Norwegian National 
Academy of Banking.

Trutkowski, C. (2019). Principles of Training Needs Analysis. [online] Rm.coe.int. Available at: https ://rm.coe.int/tna-and-nts-training-needs-analysis-and-national-training-strategies-h/1680746e54 [Accessed 1 May 2019].

Vayuvegula, A. (2017). Mobile Apps and How to Use Them for Corporate Training. [online] Custom E-learning and Online Training Blogs - CommLab India. Available at:

https://blog.commlabindia.com/elearning-development/how-to-use-mobile-apps-for-training [Accessed 2 Jul. 2019].

Wentland, D. M. (2007). Strategic Training : Putting Employees First. Amherst, Mass: HRD Press. 